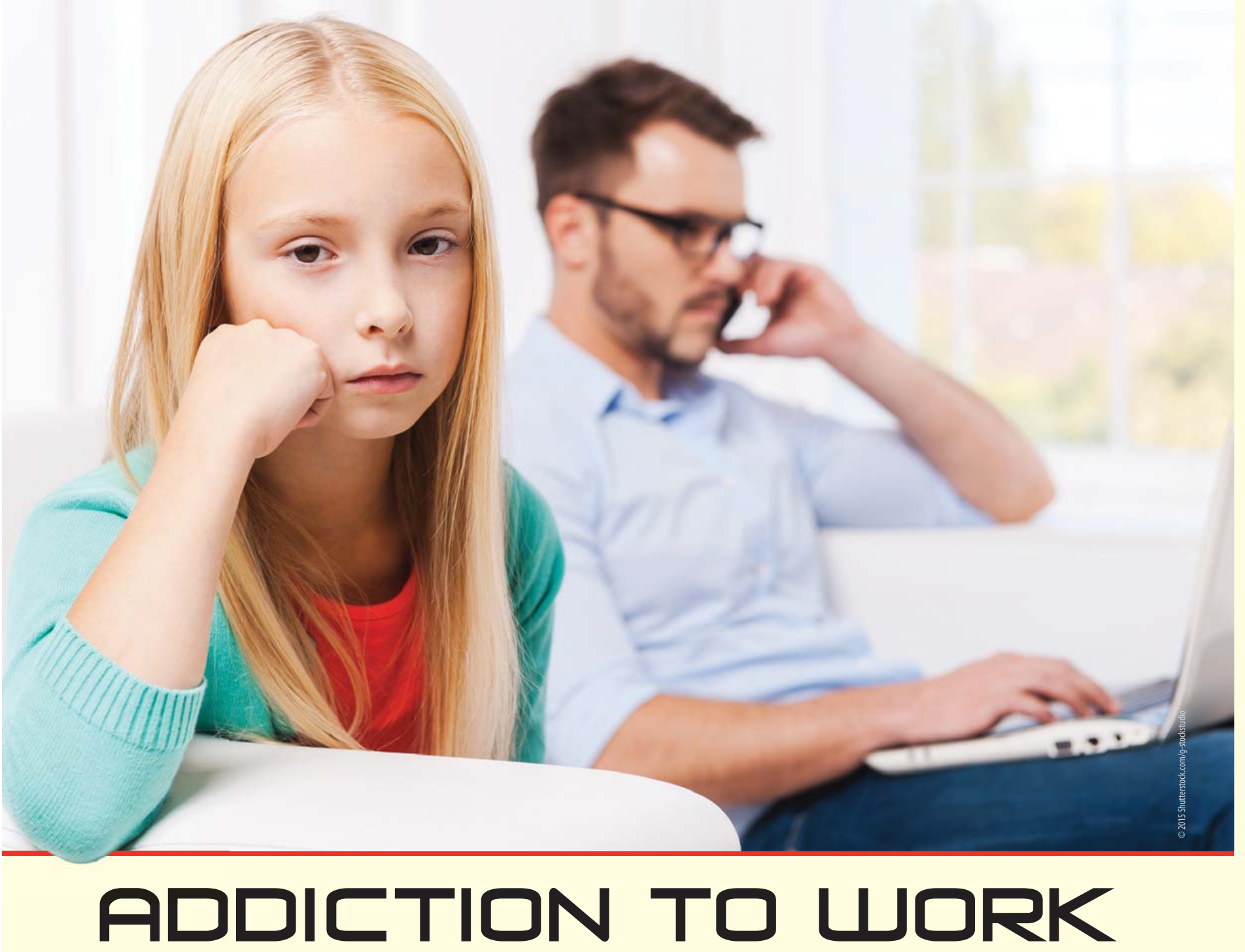

\title{
A Critical Review of the Workaholism Construct and Recommendations for Assessment
}

\section{Cristina Quinones, PhD, BSc, MSc HRM, CPsychol; and Mark D. Griffiths, PhD, BSc, CPsychol, FBPsS, FRSA, FAcSS}

\section{ABSTRACT}

Workaholism was first conceptualized in the early 1970s as a behavioral addiction, featuring compulsive use and interpersonal conflict. The current article briefly examines the empirical and theoretical literature over the past four decades. In relation to conceptualization and measurement, how the concept of workaholism has worsened from using dimensions based on anecdotal evidence, ad-hoc measures with weak theoretical foundation, and poor factorial validity of multidimensional conceptualizations is highlighted. Benefits of building on the addiction literature to conceptualize workaholism are presented (including the only instrument that has used core addiction criteria: the Bergen Work Addiction Scale). Problems estimating accurate prevalence estimates of work addiction are also presented. Individual and sociocultural risk factors, and the negative consequences of workaholism from the addiction perspective (e.g., depression, burnout, poor health, life dissatisfaction, family/relationship problems) are discussed. The current article summarizes how current research can be used to evaluate workaholism by psychiatric-mental health nurses in clinical practice, including primary care and mental health settings. [Journal of Psychosocial Nursing and Mental Health Services, 53(10), 48-59.] 


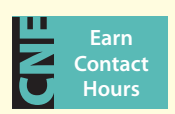

$\mathrm{T}$ he term workaholism was first used by Oates (1971) to highlight the similar cognitive-behavioral pattern that excessive and problematic work shared with alcoholism, a well-established, substance-based addiction. Oates (1971) described workaholism as a "compulsion or uncontrollable need to work incessantly" (p. 11). Following this seminal work, the addiction perspective was mostly abandoned in favor of adopting either an obsessive compulsive trait-based approach (Schaufeli, Bakker, van der Heijden, \& Prins, 2009a; Schaufeli, Shimazu, \& Taris, 2009) and/or a multi-faceted perspective including some of the following factors: quantification of the behavior (i.e., time spent working [Mosier, 1983]), motives and related attitudes (i.e., work enjoyment and job involvement [Spence $\&$ Robbins, 1992]), abilities (i.e., ability to delegate [Robinson, 1999]), and personality traits (e.g., selfworth [Robinson, 1999]).

Adoption of this multidimensional approach can be seen in some of the definitions of workaholism. For instance, McMillan, O'Driscoll, and Burke (2003) defined workaholism as "the difficulty to disengage from work, a strong drive to work, intense enjoyment and a differing use of leisure time than others" (p. 167). Unfortunately, these multifaceted conceptualizations of workaholism, such as the workaholism triad of work involvement, drive, and enjoyment of work (Spence \& Robbins, 1992), often lacked strong theoretical justification and received little empirical support. Regardless of debates in the literature, empirical evidence supports the assertion that some individuals strug- gle with problems of compulsive working and experience conflict in their lives as a result. Furthermore, in Westernized societies where individuals are increasingly subject to work intensification and 24/7 online connectivity, workaholism is likely to become even more prevalent $(\mathrm{Ng}$, Sorensen, \& Feldman, 2007). Thus, clinicians and other stakeholder groups (e.g., managers, human resources personnel) need reliable tools and guides that help identify individuals experiencing this problem and give them adequate support.

Recently, it has been argued that a robust, theoretically driven conceptualization of workaholism is possible by going back to the original addiction conceptualization of Oates (1971) and building on the strong body of knowledge of behavioral addictions (Andreassen et al., 2014; Sussman, Lisha, \& Griffiths, 2011). However, before moving on to discuss the addiction perspective and assessment, the most widely used conceptualizations and assessments of workaholism are briefly evaluated.

\section{WORKAHOLISM \\ CONCEPTUALIZATION AND ASSESSMENT}

Table 1 presents a summary of all the measures reviewed in the current article, differentiating between the original subscales, main limitations attributed to each instrument, and notes for applicability in clinical practice.

\section{Workaholism Battery Scale}

The most extensively used instrument in the field has arguably been the Workaholism Battery (WorkBat) scale developed by Spence and Robbins (1992). Based on their review of existing literature at the time, they conceptualized workaholism as a trait-based multidimensional construct comprising enjoyment, drive, and work involvement. The original instrument comprised 25 items distributed across three subscales. The inclusion of enjoyment led Spence and Robbins (1992) to distinguish between enthusiastic and nonenthusiastic workaholics. This latter group was viewed as real workaholics who, like enthusiastic workaholics, have high levels of involvement and drive but report low enjoyment from doing work. Similarly, Ng et al. (2007) conceptualized workaholism in terms of cognitive (i.e., thinking obsessively about work), behavioral (i.e., work salience and conflict), and affective dimensions. The latter included the enjoyment facet, although $\mathrm{Ng}$ et al. (2007) stressed that this referred to the actual process of working and not the content of work.

Although Spence and Robbins' (1992) conceptualization including enjoyment has been widely used in the field (McMillan et al., 2003), empirical evidence started to accumulate on the more negative side of excessive work investment (Griffiths, 2011; Robinson, 2013; Schaufeli et al., 2009a; Schaufeli, Shimazu, et al., 2009). This accumulation resulted in agreement to drop the term workaholic when work involvement was associated with enjoyment and to alternatively use the term engaged (Mudrack, 2006; Taris, Schaufeli, \& Shimazu, 2010). In addition, empirical studies have failed to confirm the threedimensional structure of the 25 -item 


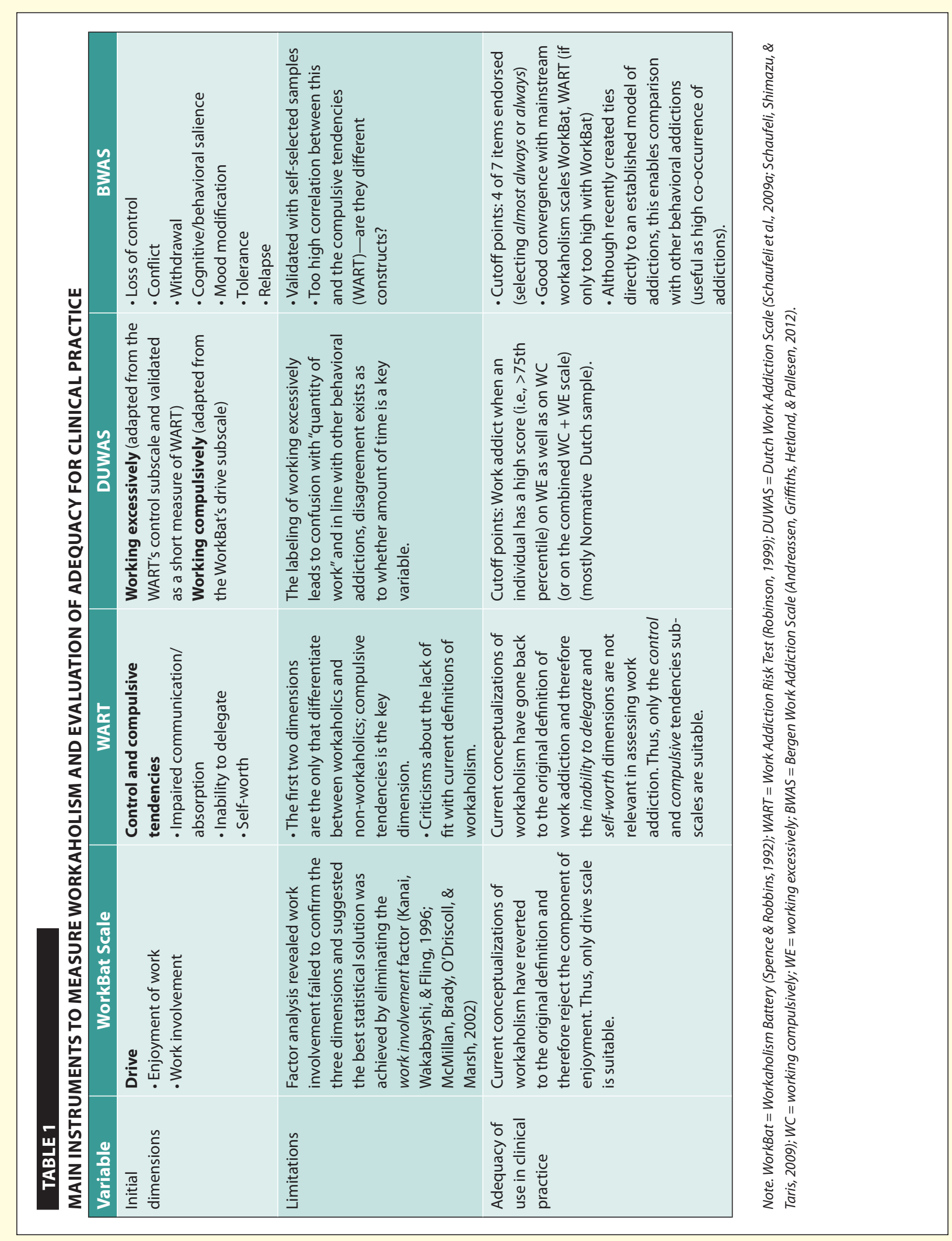


scale, with the work involvement subscale exhibiting particularly poor psychometric qualities (McMillan, Brady, O'Driscoll, \& Marsh, 2002). Furthermore, it has been argued that involvement could be omitted for the sake of parsimony as this is already captured by the other two factors, which has informed the revised WorkBat scale by McMillan et al. (2002).

\section{Work Addiction Risk Test}

The Work Addiction Risk Test (WART; Robinson, 1999) is perhaps the second most widely used assessment of workaholism. Building primarily on the experiences of clinicians treating workaholics, Robinson (1999) developed the 25-item scale comprising five subscales: (a) compulsive tendencies, (b) control, (c) impaired communication/self-absorption, (d) inability to delegate, and (e) selfworth. Subsequent studies that psychometrically tested the WART have consistently failed to support the existence of five components, with studies typically reporting between three and five factors. Also, despite the multidimensional conceptualization, the author's scoring method to diagnose workaholism is performed as a singlefactor scale (Robinson, 1999). More contemporary empirical studies suggest only compulsive tendencies and control are the key dimensions that discriminate between workaholics and non-workaholics (Flowers \& Robinson, 2002). Having only two dimensions discriminate between workaholics and non-workaholics in addition to the relatively high correlations with general anxiety and Type A personality have either deterred authors from using this instrument as indicative of workaholism or has led them to use the first two subscales only (Andreassen, 2014).

\section{Dutch Work Addiction Scale}

Another popular assessment of workaholism is the Dutch Work Addiction Scale (DUWAS; Schaufeli et al., 2009a; Schaufeli, Shimazu, et al., 2009). The authors conceptualized workaholism as a relatively stable trait within the obsessive-compulsive realm and comprised two dimensions: working excessively (i.e., working too hard) and compulsively (i.e., the inner drive to work incessantly). Unlike previous conceptualizations, the authors asserted that their proposed two-dimensional conceptualization reflected Oates' (1971) original definition. However, the actual operationalization of the scale built on items contained in the WART and WorkBat. Working compulsively is assessed with the drive subscale from WorkBat and working excessively is assessed with the compulsive tendency subscale from WART. Importantly, despite the compulsive label of the original scale, Schaufeli, Taris, and Bakker (2006) found that only two of nine items assessed compulsive tendencies (i.e., "I feel guilty when I am not working on something" and "It is hard for me to relax when I am not working"), whereas the majority of items assessed excessive work. Furthermore, factor analysis demonstrated that these particular items loaded best on the compulsive working dimension; hence, the authors recommended that these items be included in that dimension (Schaufeli et al., 2006). Nonetheless, subsequent research into the extended scale (Del Líbano, Llorens, Salanova, \& Schaufeli, 2010) still show one of the items (i.e., item 17) as a component of working excessively instead of compulsively, which may lead to confusion among individuals using the twodimensional conceptualization.

Although Schaufeli et al. (2009a) and Schaufeli, Shimazu, et al. (2009) argue that their model captures the original definition of workaholism, the diagnosis of workaholism is dependent on high scores in working excessively and compulsively. Current thinking in this field rejects the notion that excessive behavior is necessarily a key component of addiction. Excessive engagement in a specific behavior is positively correlated with addiction but cannot be used as a key in- dicator of addiction (Griffiths, 2011). Studies examining motivational dispositions of workaholism have found that working excessively is not related to controlled motivation, which is a commonly cited antecedent of the key compulsive element of workaholism (Van den Broeck et al., 2011). In addition, the excessive working scale has shown marginal internal consistency in some studies (Sussman et al., 2014). Although returning to the original addiction perspective, Schaufeli et al. (2009a) did not build on the accumulated evidence in this field and, together with the discussed issues, it limits the direct applicability of this tool for diagnosis in clinical practice.

Other workaholism assessment scales exist, but there has been little in the way of psychometric validation (e.g., the trait measure that assesses overlap with obsessive-compulsive disorder, the Schedule for Non-Adaptive Personality [SNAP-Work; Clark, McEwen, Collard, \& Hickok, 1993], or the behavioral-based instrument developed by Mudrack and Naughton [2001]). Although the tools previously discussed have broadly assisted the field in differentiating between individuals who may be at risk of experiencing negative consequences from those who may just be highly engaged with work (and therefore less at risk), they have also included additional elements, which, from an addiction perspective, have failed to be theoretically justified. Enjoying work has been recently conceptualized as an independent phenomenon that does not suit traditional addiction conceptualizations. Excessive behavior does not qualify as a key dimension of addiction on its own (Griffiths, 2011).

Furthermore, the various suggestions of multidimensionality have either not received empirical support about the number and type of dimensions proposed (i.e., from onedimensional to multifaceted, from an addiction to a personality trait, to an attitude), or have shown poor psychometric qualities (e.g., working exces- 
sively from the DUWAS or work involvement from the WorkBat). There has been little effort to examine convergent and discriminant validity between these multiple measures. Critiques, such as those by Andreassen (2014) and $\mathrm{Ng}$ et al. (2007), argue that these different instruments have been driven empirically rather than theoretically. Consequently, there could be lack of convergent validity among the instruments developed. Therefore, a psychometrically valid and reliable diagnostic tool has been called for to understand the prevalence and impact of workaholism and help in the development of targeted interventions.

\section{Syndrome Model of Workaholism}

Because workaholism was first framed as a behavioral addiction and given the accumulated empirical evidence from within the addictions field (behavioral- and substance-based), supporting a syndrome-based model of addictions regardless of the object of addiction (Shaffer et al., 2004), a number of researchers have been persuaded that such addiction literature could help advance the understanding of the key components of workaholism. The syndrome-based model of addiction suggests that similar underlying mechanisms operate regardless of the object of addiction and that manifestations of the syndrome will be generic and unique to the specific addiction. Similar underlying vulnerabilities may be operating along with more unique psychosocial variables that predispose individuals to interact with a particular object of addiction and no other.

Increasing research evidence in the field is supportive of such a model. Thus, for instance, self-report multiaddiction survey studies have found strong correlation among different behavioral and substance addictions (Villella et al., 2011). Furthermore, an increasing number of studies report chemical and behavioral addictions share similar course, history, and neurobiological correlates (Grant,
Potenza, Weinstein, \& Gorelick, 2010; Griffiths, 2005; Orford, 2001). In relation to the similarity in history of drug and behavioral addictions, Carroll and Robinson (2000) found that undergraduate students who were children of alcoholics or workaholics were more likely to adopt such behaviors from their parents earlier in their lives compared to the other students, and they reported their parents' workaholism or alcoholism as the reason for them to do so. Perhaps the most compelling evidence comes from neurological studies, as these support the hypothesis that (a) reward circuits in the brain are involved in substanceand non-substance-based addictions, (b) both share similar genetic vulnerability and clinical features, and (c) that they develop following a similar pattern (i.e., initial arousal before the act, pleasure/high relief linked to the act, and lowered arousal afterward with guilt, withdrawal, and potential tolerance) (Grant et al., 2010; Villella et al., 2011).

\section{BACK TO BASICS: USING ADDICTION LITERATURE TO THEORIZE WORKAHOLISM}

Oates' (1971) original conceptualization of workaholism reflected a pure addiction perspective in terms of the compulsion to work and degree of conflict with one's life: "A workaholic is a person whose need for work has become so excessive that it creates noticeable disturbance or interference with his bodily health, personal happiness, and interpersonal relations, and with his smooth social functioning" (p. 4).

Two highly influential models in the understanding of behavioral addictions are the syndrome model of addiction (Shaffer et al., 2004) and component model of addiction (Griffiths, 2005). Whereas the former has been most helpful in understanding antecedents and vulnerability, the latter provides a framework on which the key underlying features of addiction can be understood. The component model draws on Brown's
(1993) hedonic management model and has been largely inspired by the diagnostic classification of pathological gambling in the fourth edition of the Diagnostic and Statistical Manual of Mental Disorders (American Psychiatric Association, 2000). According to this framework, an addict displays symptoms that represent each of the following components: cognitive and/ or behavioral salience (i.e., the activity dominates thoughts and/or behavior), mood modification (i.e., the behavior is used as a way to modify mood), tolerance (i.e., the increasing amount of time required to obtain the same experience with the activity), withdrawal symptoms (i.e., feeling negative emotions when the activity is stopped or diminished), relapse and reinstatement, loss of control (i.e., the need to return to the same level of use after trying to stop and losing control over the use), and conflict (i.e., the behavior conflicts with everything in the individual's life, such as relationships, job, and/or education) (Brown, 1993; Griffiths, 2005).

\section{Bergen Work Addiction Scale}

The component model of addictions has been validated in a variety of substance- and non-substance-based addictions and has been widely used to develop tools to understand and assess prevalence across a number of different addictions, such as gaming (Griffiths, 2002), exercise (Allegre, Souville, Therme, \& Griffiths, 2006), and Internet addiction (Widyanto \& Griffiths, 2006), and, more recently, social networking addiction (Andreassen, Tosheim, BrunBerg, \& Pallesen, 2012). Building on these findings, Andreassen, Griffiths, Hetland, and Pallesen (2012) developed the Bergen Work Addiction Scale (BWAS). The scale comprises seven items tapping into each of the aforementioned components and each item is scored on a 5-point Likert scale where $1=$ never and 5 = always. Individuals are operationally classified as workaholics if they endorse four or more of seven items (i.e., 
scoring often or always). Although still in relative infancy, it has already been validated in Norwegian samples of more than 12,000 individuals and has a one-dimensional structure, and high Cronbach's alphas ranging from 0.80 to 0.85 . Convergent and discriminant validity analysis suggest that the BWAS converges well with existing workaholism scales tapping the compulsive element (range $=0.50$ to 0.84 ), although the correlation tool to advance understanding of workaholism. However, users should be aware that considering how recently it was developed, it still needs further cross-cultural validation.

\section{PREVALENCE OF WORKAHOLISM}

The scarcity of studies, together with the different methods to assess workaholism and the limited representative sampling techniques, does not allow the reporting of ac-

\section{Regardless of debates in the literature, empirical evidence supports the assertion that some individuals struggle with problems of compulsive working and experience conflict in their lives as a result.}

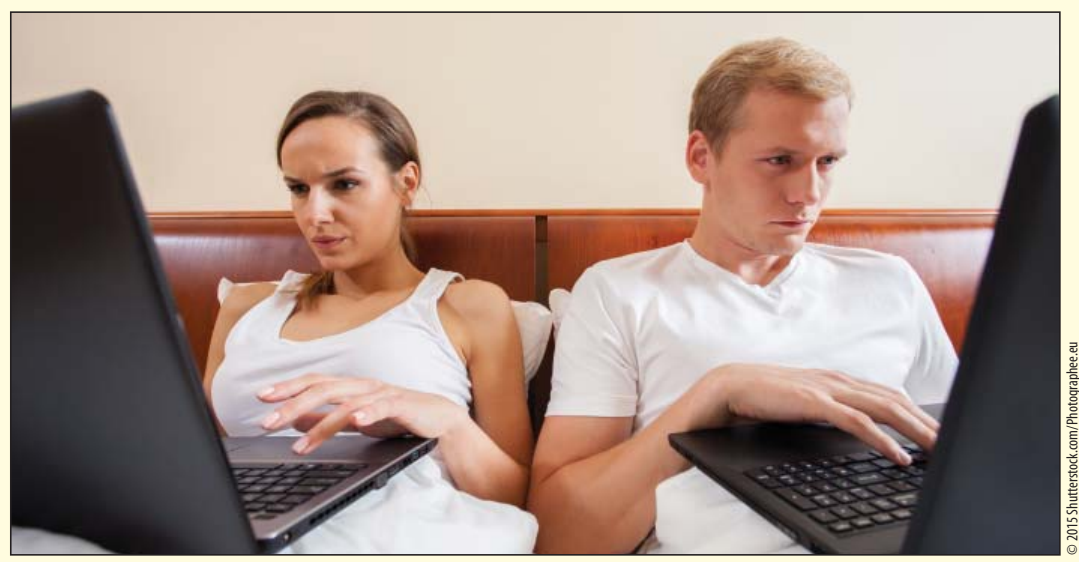

with the compulsive tendencies subscale was high to warrant attention of potential duplication. The correlation with the WorkBat enjoyment subscale was low (0.13), supporting the view that engagement and workaholism are two different constructs (van Beek, Taris, \& Schaufeli, 2011).

Given the strong conceptual foundation and brevity of the scale (i.e., favoring its use for prevalence studies or for screening within the workplace), and considering its operationalization enables integration of work addiction with potential co-occurring addictions, the BWAS is a promising curate prevalence estimates. Similar to other behavioral addictions, early approaches in examining prevalence of workaholism were concerned with assessing excessive amounts of behavior either measured in number of hours (as a proxy for workaholism) or directly asking individuals about their perceptions. For instance, Matuska (2010) reported that, in a national Canadian survey in 2005, one third of the working-age population self-diagnosed as workaholics. Extrapolating these figures to the American population in employment age and among those actually em- ployed, Sussman (2012) estimated an approximate $18 \%$ prevalence of workaholism. However, the ad-hoc selfreport measure used in the Canadian study raises questions about the accuracy of prevalence figures. A study conducted by Burke and Ng (2006) comparing self-reports of workaholism with colleagues' reports of workaholic behavior were highly similar.

A more sophisticated method of prevalence estimation is the multiaddiction matrix. This matrix comprises providing a rigorous definition of addiction and evaluating the extent to which respondents believe they are addicted to one or more of the objects typically including behaviors such as sex, relationships, work, and psychoactive substances (Cook, 1987; Sussman et al., 2011, 2014). Cook (1987) was a pioneer in this matrix method when he developed the Problem History Questionnaire that built on Peele's (1985) conceptualization of addiction. In the development study with college students, work addiction was one of the most prevalent addictions (17.5\%). Building on matrix methods, Sussman et al. (2014) examined the prevalence of multiple addictions in alternative high school students who had been part of a drug abuse prevention program 3 years prior to data collection. The authors found that $20 \%$ of respondents reported having been addicted to work. The figures were slightly lower when respondents were asked about the past 30 days $(15.6 \%)$. Although this was a young at-risk sample that reported significantly higher than normal levels of substance-based addictions, the difference with the general adult population in relation to this particular addiction within a 12 -month period did not differ significantly from large adult samples from Canada, where work and eating were the most prevalent behavioral addictions (Konkolÿ Thege et al., 2015).

Unlike these ad-hoc instruments, most of the 16 addictive behaviors subscales included in the Short PROMIS Questionnaire (SPQ; Christo et al., 
2003) have been validated in clinical samples. Using this instrument, MacLaren and Best (2010) reported a $12.4 \%$ prevalence of work addiction among university students. However, the work addiction subscale from SPQ was one of the subscales that did not have any criterion validity. Villella et al. (2011) reported a more conservative figure of $8.5 \%$ workaholics among a high school sample using the WART. It should be noted that assessing work addiction in students arguably lacks face validity, as the majority are not in full-time employment.

Given the variety of prevalence figures and methods used, Sussman et al.'s (2011) meta-analysis roughly estimated a middle point of approximately $10 \%$ addiction to work. Prevalence figures have also been investigated separately for different occupational groups, as there are studies suggesting this can be more prevalent in particular occupations. For instance, using the WorkBat, Burke (2000) found $16 \%$ of workaholics in a sample of professional managers (i.e., individuals with high drive, low enjoyment, and high involvement). Psychologists, medical doctors, and lawyers are also occupations reporting high levels of workaholism (up to 23\%) (Doerfler \& Kammer, 1986). It should be highlighted that until authors define and assess work addiction in a consistent way using widely validated instruments, any prevalence estimate can only offer an approximation to the real size of the problem. Overcoming these limitations, Andreassen et al. (2014) conducted the first ever nationally representative prevalence study among Norwegian adult employees $(N=1,124)$ using the BWAS. The authors reported a work addiction prevalence rate of $8.3 \%$, with the most highly endorsed components of the multicomponent model of addiction being tolerance, conflict, and withdrawal.

\section{WHO IS AT RISK?}

The lack of agreement among scholars about the nature and true dimensions of workaholism limits the ability to accurately identify potential risk factors. In the absence of longitudinal studies, differentiating between antecedents and consequences rather than correlates is often a matter of theoretical elaboration, often extrapolating evidence from related areas of research. From a classical learning theory perspective, the increased risk of workaholism would be in the contingency between work behavior and external reinforcement that could be positive (e.g., meaningful rewards administered if the behavior of working hard is executed) or negative (e.g., engaging in the behavior frees one from engaging in unwanted alternative behaviors, such as spending time with a partner in the context of an unhappy relationship). However, this theory is built on the assumption that individuals are externally controlled by reinforcers and gives little room for individual dispositional variables. Learning theory clashes with the seemingly stable nature of workaholism across the lifespan and studies have demonstrated strong links between workaholism and personality traits (Andreassen et al., 2014; Spence \& Robbins, 1992).

Currently, it is accepted that a combination of individual dispositions (e.g., biological/genetic predispositions, personality traits), together with specific beliefs and values resulting from the interaction between one's predisposition and the sociocultural and organizational environment, contribute to the development of work addiction ( $\mathrm{Ng}$ et al., 2007). From a personality trait perspective, at-risk individuals may exhibit a combination of compulsivity, obsessiveness, and perfectionism at the simplest level, and neuroticism and conscientiousness at a higher-order level (Spence \& Robbins, 1992; Stoeber, Davis, \& Townley, 2013). Need for achievement has been regarded as a strong predictor of workaholism $(\mathrm{Ng}$ et al., 2007). Feelings of low self-worth have been identified as drivers of workaholism as employees can use work as a means to address these negative feelings (Mudrack, 2006; Ng et al., 2007).
From a cognitive psychology perspective, values such as achievement and self-direction are particularly relevant to understand workaholism. Individuals who strongly uphold these values want to be successful and influential, which results in them working excessively to behave in consonance with their values ( $\mathrm{Ng}$ et al., 2007). Within the cognitive perspective (and from a more pathological perspective) it has been argued that problematic core beliefs about the self lead to assumptions about the cause of those beliefs and automatic thoughts (e.g., low self-esteem leads to "working will make me feel better" and "I will work hard") (McMillan et al., 2003).

Individual motives have also been explored as antecedents of workaholism and, in particular, SelfDetermination Theory (van Beek et al., 2011; van Beek, Hu, Schaufeli, Taris, \& Schreurs, 2012) has been used to explore these relationships. Self-Determination Theory broadly distinguishes between behavior that is autonomously motivated and externally controlled (Ryan \& Deci, 2000). Early studies suggested that work-related rewards (i.e., externally controlled motivators) can be essential motivators for workaholics (Spence \& Robbins, 1992). More recently, attention has been paid to a less obvious type of controlled motivation, labeled introjected regulation. Introjected regulation results from partially internalizing external standards of social approval and self-worth; hence, the standards have been internalized but individuals do not fully identify with them and can be at odds with other personal values (Ryan \& Deci, 2000). van Beek et al. (2011, 2012) found that this particular type of motivation, and not just the purely externally controlled motivation, was a key predictor of workaholism. Stoeber et al. (2013) found that introjected regulation was a strong predictor of workaholism and that this variable appeared to fully explain the impact of the perfectionism personality trait on workaholism. In this sense, the 
workaholic does not engage in the behavior to enjoy it, but for its instrumental value. Meeting the external standards helps workaholics improve their self-worth and failing to do so results in negative feelings deeply connected to the self, such as shame and guilt (Killinger, 2006).

Researchers have examined beliefs and values that incorporate the influence of the sociocultural environment, and that are acquired in the socialization process. In this sense, highly demanding families might raise their children while reinforcing the values of effort and discipline from early in life. These values are acquired through a combination of operant conditioning and vicarious learning mechanisms. Indirect support for the early adoption of these values was found in a study that examined the children of workaholics (Carroll \& Robinson, 2000). The authors found that these children adopted their parents' workaholic values and behaviors and involved a higher degree of responsibility compared to children of non-workaholic parents. Later in life, professional rules (implicit or explicit), along with those of the organizations in which individuals work, may play a key role in feeding the thirst for working compulsively (e.g., long working hour cultures, tangible and intangible rewards). In a large study of professional and managerial jobs, Burke (2001) found that workaholics were more likely to work in organizations that had more work-personal imbalance practices (e.g., travelling to and from the workplace during weekends, lack of limits relating to hours spent at work) compared to non-workaholics. Living in a modern 24/7 connectivity society, technology provides the best and worst excuses for individuals with predispositions to materialize their urges.

Although there is still much work to be done in this area, an understanding of how these different variables contribute to developing workaholism will help psychiatric-mental health nurses and other relevant stakeholders

\section{KEYPOINTS}

Quinones, C., \& Griffiths, M.D. (2015). Addiction to Work: A Critical Review of the Workaholism Construct and Recommendations for Assessment. Journal of Psychosocial Nursing and Mental Health Services, 53(10), 48-59.

1. Workaholism is a term used to describe individuals' addiction to work and has been associated with highly detrimental consequences for individuals' health, including depression, burnout, poor health, life dissatisfaction, and family/ relationship problems.

2. Differentiating between highly work-engaged individuals and those addicted to work has been fraught with difficulty due to poorly conceptualized instruments and poor factorial validity.

3. The Bergen Work Addiction Scale is the first instrument to build on a widely validated model of addictions and offers a quick and simple tool to differentiate between highly engaged individuals and those addicted to work.

4. Having an understanding of potential risk factors is important in the diagnosis of work addiction. These risk factors include a combination of individual dispositions (e.g., biological/genetic predispositions, personality traits) and specific beliefs and values resulting from the interaction between one's predisposition and sociocultural and organizational environment.

Do you agree with this article? Disagree? Have a comment or questions?

Send an e-mail to the Journal at jpn@healio.com.

(e.g., managers, human resource personnel) design prevention and relapse strategies while living within a context of increased job intensification partly supported by technological advance.

\section{CONSEQUENCES OF \\ WORKAHOLISM}

Given that most studies performed in the work addiction field rely on cross-sectional designs, the classification of covariates as antecedents and/or consequences has strong methodological limitations. Perhaps a more sensible approach could be to identify correlates that should be considered simultaneously when evaluating how workaholism is affecting (or could affect) an individual's life and that of his/her family and close friends. It is important to note that workaholism is sometimes confused with work engagement, resulting in the attribution of positive consequences to work addiction (van Beek et al., 2012). This notion is misleading, as individuals who experience conflict in their lives due to recurrent workaholic behavior have lower productivity levels, experience chronic stress, and are far more likely to be absent from work and have longer illness periods (Andreassen et al., 2014; Sussman, 2012). Ng et al. (2007) suggest that differentiating between short-term gains and long-term costs could be useful to understand the mixed outcomes that workaholics may experience.

Studying workaholism from the addiction perspective results in a number of specific negative consequences-most notably loss of control, withdrawal, conflict, and behavioral salience. Beyond this, workaholism has been consistently associated with burnout (Innanen, Tolvanen, \& Salmela-Aro, 2014; Schaufeli et al., 2009b). In fact, De Carlo et al. (2014) found that workaholism mediated the relationship between regulatory focus (i.e., motivational dispositions) and burnout. Workaholism has also been associated with depression (Carroll \& Robinson, 2000), poorer physical health ( $\mathrm{Ng}$ et al., 2007), career and 


\section{TABLE 2}

\section{THE BERGEN WORK ADDICTION SCALE}

\begin{tabular}{|l|c|}
\hline Item & Addiction Component \\
\hline $\begin{array}{l}\text { How often during the last year have you... } \\
\text { work? }\end{array}$ & Salience \\
\hline $\begin{array}{l}\text { 2. Spent much more time working than initially } \\
\text { intended? }\end{array}$ & Tolerance \\
\hline $\begin{array}{l}\text { 3. Worked in order to reduce feelings of guilt, } \\
\text { anxiety, helplessness and depression? }\end{array}$ & Mood modification \\
$\begin{array}{l}\text { 4. Been told by others to cut down on work without } \\
\text { listening to them? }\end{array}$ & Relapse \\
\hline $\begin{array}{l}\text { 5. Become stressed if you have been prohibited from } \\
\text { working? }\end{array}$ & Withdrawal \\
$\begin{array}{l}\text { 6. Deprioritized hobbies, leisure activities, and } \\
\text { exercise because of your work? }\end{array}$ & Conflict \\
\hline $\begin{array}{l}\text { 7. Worked so much that it has negatively influenced } \\
\text { your health? }\end{array}$ & Problems \\
\hline
\end{tabular}

Note. Items scored on a 5-point scale, where $1=$ never, $2=$ rarely, $3=$ sometimes, $4=$ often, and $5=$ always. Adapted from Andreassen, Griffiths, Hetland, and Pallesen (2012).

life dissatisfaction (Bonebright, Clay, \& Ankenmann, 2000), work-family conflict (Bonebright et al., 2000; Matuska, 2010; Shimazu, Demerouti, Bakker, Shimada, \& Kawakami, 2011), and higher level of conflict in relationships and marital problems (Robinson, Carroll, \& Flowers, 2001). In a time series study (i.e., a more sophisticated design to assess consequences than the more frequently used cross-sectional surveys), Bakker, Demerouti, Oelermans, and Sonnentag (2013) confirmed that working during the evening was more harmful in terms of well-being for workaholics than for non-workaholics.

\section{CO-OCCURRING ADDICTIONS}

In addition to theoretically driven consequences and given the addiction origins of the workaholism concept, researchers have become increasingly interested in the study of behaviors that co-occur with workaholism, such as substance-based addictions, as this can lead to the adoption of a more holistic approach to prevent and treat such problems effectively (Shaffer et al., 2004). The syndrome model of addiction hypothesizes that individuals who develop an addiction (behavioral or chemical) experience an alteration of their reward system that increases their likelihood of developing new addictions in relation to objects to which they are frequently exposed (Shaffer et al., 2004). For instance, coffee, which can be found at work and home, can aid alertness and productivity. Workaholism and coffee drinking often co-occur and, when they do, are likely to reinforce one other (Porter \& Kakabadse, 2006).

Given the few studies estimating the prevalence of workaholism, co-occurrence studies are even harder to find. Carnes (1991) examined other addictions in a large sample of sex addicts and claimed that 23\% were also work addicts. The metaanalysis performed by Sussman et al. (2011) in U.S. adult populations reported an estimated $47 \%$ of individuals experienced an addiction to one of 11 substances and behaviors, including work, over a 12 -month period. The degree of co-occurrence between two or more of those addictions was estimated at 23\% (substances included cigarettes, alcohol, and hard drugs, and behaviors included eating, gambling, using the Internet, shopping, love, sex, exercise, and work). In particular, they reported a 20\% degree of co-occurrence between workaholism and other addictions; however, whether this is higher for some of these addictions than for others is unknown.

It has been argued that the type of behavioral addiction that individuals are likely to develop following a previous one can be predicted from their lifestyles (Sussman et al., 2011; Sussman, 2012). Because work and technology are often intertwined and work is reliant on the use of technology, co-occurrence of these two phenomena has been the focus of recent empirical studies. Porter and Kakabadse (2006) conducted a qualitative study with information technology professionals and concluded that work and Internet addiction mutually reinforced one other. This reinforcing mechanism was later examined in a quantitative two-wave study by Quinones, Griffiths, and Kakabadse (2015), who found that Internet addiction appeared to be the antecedent for work addiction. The authors tentatively explained this result, building on Carnes, Murray, and Charpentier's (2005) model of addiction, via the "masking mechanism" (p. 94). This mechanism describes how individuals engage in a more socially acceptable addiction (i.e., workaholism, a socially rewarded addiction) as a strategy to hide or cover an addiction that is less socially acceptable (e.g., Internet addiction, a non-socially rewarded addiction). Although the study was not truly longitudinal, it nonetheless could contribute to the development of more rigorous studies capable of exploring co-occurrence in a more systematic way. 


\section{IMPLICATIONS FOR DIAGNOSIS OF WORKAHOLISM IN PSYCHIATRIC- MENTAL HEALTH NURSING \\ PRACTICE}

Although the field is still in development, individuals who experience workaholism need to be appropriately supported. There have been some suggestions to assess workaholism within clinical practice. Robinson (1998) cited 10 signs to watch for: (a) hurrying and staying busy, (b) need to control, (c) perfectionism, (d) difficulty with relationships, (e) work binges, (f) difficulty relaxing and having fun, (g) memory losses of conversations or trips to and from a destination because of exhaustion and mental preoccupation with planning and work effects of tuning out the present, (h) impatience and irritability, (i) self-inadequacy, and ( $\mathrm{j}$ ) selfneglect.

These 10 signs highlight some of the important aspects to be considered when examining workaholism, but they do not provide any norms for diagnosis or suggest how many and in what combination these signs suggest potential workaholism. As argued throughout the current article, the addiction literature provides the most promising framework from which to study workaholism. In view of this, the current authors suggest that the BWAS (Andreassen, Griffiths, et al., 2012) be used as a tool to help psychiatric-mental health nurses identify individuals who might struggle with work addiction in addition to other problems, or as the main cause of their discomfort. Below, the advantages and disadvantages of the scale are summarized so that psychiatricmental health nurses (and other stakeholders, such as managers and human resources personnel) understand the contribution of the tool to their practice.

\section{THE BERGEN WORK ADDICTION SCALE: NURSING ASSESSMENT OF WORK ADDICTION}

The advantages of the BWAS are that the tool: (a) is rooted in addic- tion theory as opposed to dimensions shown to have poor validity, (b) is unidimensional (although multidimensional scales have been developed, empirical evidence justifying these is often scarce and theoretically unsupported), (c) has clear cutoff points aligned with other psychiatric measures, (d) was validated using two large samples, and (e) has good specificity (the 4 of 7 cutoff point differentiates well between workaholics and non-workaholics based on the number of hours and subjective health complaints). However, it should be used with caution on the understanding that: (a) there is no gold standard against which to evaluate the cutoff point so there is a potential risk to over-diagnose (although it is important to highlight that other diagnostic tools use less stringent criteria [typically 5 of 10]); (b) work addiction has not yet been recognized as a psychiatric disorder so even if the instrument is used to identify the problem, this should never be equated with a psychopathology in strict psychiatric terms; and (c) it requires further validation studies in different countries (Table 2).

\section{CONCLUSION}

The current article briefly examines the history of workaholism and argues that the best way to understand potential problems is from a behavioral addiction perspective. Workaholism is a serious issue and can lead to physical and psychological problems (e.g., depression, burnout, poor health, life dissatisfaction, family/relationship problems) as well as negatively impact organizations that individuals work for (e.g., work absence, loss of productivity). Workaholism is a multifaceted behavior strongly influenced by individual, contextual, and structural factors (including involvement and motivation, job design, and the temporal nature of addictive work behavior). It should be reiterated that excessive working does not necessarily mean that an individual is addicted to work and, although all genuine work addicts work excessively, not all excessive workers are addicted (Griffiths, 2011). The key issue for psychiatric-mental health nurses is whether excessive working is prolonged and to what extent excessive working negatively and detrimentally impacts other areas of workers' lives. Nurses must assess for behavioral and chemical addictions in primary care and psychiatric-mental health clinical settings. Nurses can inquire into work habits when clients present with cardiac and autoimmune conditions, and on suspicion that symptoms disclosed by clients may be due to underlying work addiction. Similar to chemical addictions, clients may be ashamed to bring up the issue unless specifically asked about stressors, symptoms, and work addiction behaviors that are assessed through a variety of instruments.

\section{REFERENCES}

Allegre, B., Souville, M., Therme, P., \& Griffiths, M.D. (2006). Definitions and measures of exercise dependence. Addiction Research and Theory, 14, 631-646.

American Psychiatric Association. (2000). Diagnostic and statistical manual of mental disorders (4th ed., text rev.). Washington, DC: Author.

Andreassen, C.S. (2014). Workaholism: An overview and current status of the research. Journal of Behavioral Addictions, 3, 1-11. doi:10.1556/JBA.2.2013.017

Andreassen, C.S., Griffiths, M.D., Hetland, J. Kravina, L., Jensen, F., \& Pallesen, S. (2014). The prevalence of workaholism: A survey study in a nationally representative sample of Norwegian employees. PLoS ONE, 9, e102446. doi:10.1371/journal.pone.0102446

Andreassen, C.S., Griffiths, M.D., Hetland, J., \& Pallesen, S. (2012). Development of a Work Addiction Scale. Scandinavian Journal of Psychology, 53, 265-272. doi:10.1111/j.14679450.2012.00947.x

Andreassen, C.S., Tosheim, T., BrunBerg, G.S., \& Pallesen, S. (2012). Development of a Facebook Addiction Scale. Psychological Reports, 110, 501-517.

Bakker, A.B., Demerouti, E., Oerlemans, W., \& Sonnentag, S. (2013). Workaholism and daily recovery: A day reconstruction study of leisure activities. Journal of Organizational Behavior, 34, 87-107. doi:10.1002/job.1796

Bonebright, C.A., Clay, D.L., \& Ankenmann, R.D (2000). The relationship of workaholism with work-life conflict, life satisfaction, and purpose in life. Journal of Counseling Psychology, 47, 469. 477. doi:10.1037/0022-0167.47.4.469 
Brown, R.I.F. (1993). Some contributions of the study of gambling to the study of other addictions. In W.R. Eadington \& J. Cornelius (Eds.), Gambling behavior and problem gambling. Reno, NV: University of Nevada Press.

Burke, R.J. (2000). Workaholism in organizations: The role of personal beliefs and fears. Anxiety, Stress and Coping, 13, 53-64. doi: $10.1080 / 10615800008248333$

Burke, R.J. (2001). Workaholism in organizations: The role of organizational values. Personnel Review, 30, 637-645. doi:10.1108/ EUM0000000005977

Burke, R.J., \& Ng, E.S.W. (2006). Workaholic behaviors: Do colleagues agree? International Journal of Stress Management, 14, 312-320. doi: $10.1037 / 1072-5245.14 .3 .312$

Carnes, P. (1991). Don't call it love: Recovery from sexual addiction. New York, NY: Bantam.

Carnes, P.J., Murray, R.E., \& Charpentier, L. (2005). Bargains with chaos: Sex addicts and addiction interaction disorder. Sexual Addiction and Compulsivity, 12, 79-120. doi:10.1080/1072016050020137

Carroll, J.J., \& Robinson, B.E. (2000). Depression and parentification among adults as related to parental workaholism and alcoholism. Family Journal: Counseling and Therapy for Couples and Families, 8, 360-367.

Christo, G., Jones, S.L., Haylett, S., Stephenson, G.M., Lefever, R.M., \& Lefever, R. (2003) The Shorter PROMIS Questionnaire: Further validation of a tool for simultaneous assessment of multiple addictive behaviours. Addictive Behaviors, 28, 225-248. doi:10.1016/ S0306-4603(01)00231-3

Clark, L.A., McEwen, J.L., Collard, L.M., \& Hickok, L.G. (1993). Symptoms and traits of personality disorder: Two new methods in their assessment. Psychological Assessment, 5, 81-91.

Cook, D.R. (1987). Self-identified addictions and emotional disturbances in a sample of college students. Psychology of Addictive Behaviors, 1, 55-61.

De Carlo, N.A., Falco, A., Pierro, A., Dugas, M., Kruglanski, A.W., \& Higgins, E.T. (2014). Regulatory mode orientations and well-being in an organizational setting: The differential mediating roles of workaholism and work engagement. Journal of Applied Social Psychology, 44, 725-738. doi:10.1111/ jasp. 12263

Del Líbano, M., Llorens, S., Salanova, M., \& Schaufeli, W. (2010). Validity of a brief workaholism scale. Psicothema, 22, 143-150.

Doerfler, M.C., \& Kammer, P.P. (1986). Workaholism, sex, and sex role stereotyping among female professionals. Sex Roles, 14, 551-560.

Flowers, C.P., \& Robinson, B. (2002). A structural and discriminant analysis of the work addiction risk test. Educational and Psychological Measurement, 62, 517-526. doi: $10.1177 / 00164402062003008$

Grant, J.E., Potenza, M.N., Weinstein, A., \& Gorelick, D.A. (2010). Introduction to behavioral addictions. American Journal of Drug and Alcohol Abuse, 36, 233-241. doi:10.3109/00952990.2010.491884

Griffiths, M.D. (2002). Gambling and gaming addictions in adolescence. Leicester, UK: BPS Blackwell.

Griffiths, M.D. (2005). A components model of addiction within a biopsychological framework. Journal of Substance Use, 10, 191-197.

Griffiths, M.D. (2011). Workaholism: A 21st century addiction. The Psychologist: Bulletin of the British Psychological Society, 24, 740. 744 .

Innanen, H., Tolvanen, A., \& Salmela-Aro, K. (2014). Burnout, work engagement and workaholism among highly educated employees: Profiles, antecedents and outcomes. Burnout Research, 1, 38-49. doi:10.1016/j.burn.2014.04.001

Kanai, A., Wakabayashi, M., \& Fling, S. (1996). Workaholism among employees in Japanese corporations: An examination based on the Japanese version of the workaholism scales. Japanese Psychological Research, 38, 192-203. doi:10.1111/j.1468-5884.1996 tb00024.x

Killinger, B. (2006). The workaholic breakdown syndrome. In R. Burke (Ed.), Research companion to working time and work addiction (pp. 61-88). Cheltenham, UK: Edward Elgar.

Konkolÿ Thege, B., Colman, I., el-Guebaly, N., Hodgins, D.C., Patten, S.B., Schopflocher, D.,...Wild, T.C. (2015). Social judgments of behavioral versus substance-related addictions: A population-based study. Addictive Behaviors, 42, 24-31. doi:10.1016/j. addbeh.2014.10.025

MacLaren, V.V., \& Best, L.A. (2010). Multiple addictive behaviors in young adults: Student norms for the Shorter PROMIS Questionnaire. Addictive Behaviors, 35, 252-255. doi:10.1016/j.addbeh.2009.09.023

Matuska, K.M. (2010). Workaholism, life balance, and well-being: A comparative analysis. Journal of Occupational Science, 17, 104. 111. doi:10.1080/14427591.2010.9686681

McMillan, L.H.W., Brady, E.C., O'Driscoll, M.P., \& Marsh, N.V. (2002). A multifaceted validation study of Spence and Robbins' (1992) workaholism battery. Journal of Occupational and Organisational Psychology, 75, 357-368. doi:10.1348/096317902320369758

McMillan, L.H.W., O’Driscoll, M.P., \& Burke, R.J. (2003). Workaholism: A review of theory, research, and future directions. In C.L. Cooper \& I.T. Robertson (Eds.), International review of industrial and organizational psychology (Vol. 18, pp. 167-189). New York, NY: Wiley.

Mosier, S.K. (1983). Workaholics: An analysis of their stress, success, and priorities (Unpublished master's thesis). University of Texas, Austin, TX.
Mudrack, P.E. (2006). Understanding workaholism: The case for behavioral tendencies. In R.J. Burke (Ed.), Research companion to working time and work addiction (pp. 108128). Northampton, MA: Edward Elgar.

Mudrack, P.E., \& Naughton, T.J. (2001). The assessment of workaholism as behavioral tendencies: Scale development and preliminary empirical testing. International Journal of Stress Management, 8, 93-111. doi:10.1023/A:1009525213213

Ng, T.W.H., Sorensen, K.L., \& Feldman, D.C. (2007). Dimensions, antecedents, and consequences of workaholism: A conceptual integration and extension. Journal of Organizational Behavior, 28, 111-136. doi: $10.1002 /$ job.424

Oates, W. (1971). Confessions of a workaholic: The facts about work addiction. New York, NY: World.

Orford, J. (2001). Conceptualizing addiction: Addiction as excessive appetite. Addiction, 96, 15-31. doi:10.1080/09652140020016932

Peele, S. (1985). The meaning of addiction: Compulsive experience and its interpretation. Lexington, MA: Lexington Books.

Porter, G., \& Kakabadse, N.K. (2006). HRM perspectives on addiction to technology and work. Journal of Management Development, 25, 535-560. doi:10.1108/02621710610670119

Quinones, C., Griffiths, M., \& Kakabadse, N. (2015). Compulsive Internet use and workaholism: An exploratory two-wave longitudinal study. Manuscript submitted for publication.

Robinson, B.E. (1998). The workaholic family: A clinical perspective. American Journal of Family Therapy, 26, 65-75. doi:10.1080/01926189808251087

Robinson, B.E. (1999). The work addiction risk test: Development of a tentative measure of workaholism. Perceptual and Motor Skills, 88, 199-210.

Robinson, B.E. (2013). Chained to the desk: A guidebook for workaholics, their partners and children, and the clinicians who treat them (3rd ed.). New York, NY: New York University Press.

Robinson, B.E., Carroll, J.J., \& Flowers, C. (2001). Marital estrangement, positive affect, and locus of control among spouses of workaholics and spouses of nonworkaholics: A national study. American Journal of Family Therapy, 29, 397-410. doi:10.1080/01926180127624

Ryan, R.M., \& Deci, E.L. (2000). Selfdetermination theory and the facilitation of intrinsic motivation, social development, and well-being. American Psychologist, 55, 68-78.

Schaufeli, W.B., Bakker, A.B., van der Heijden, F.M.M.A., \& Prins, J.T. (2009a). Workaholism among medical residents: It is the combination of working excessively 
and compulsively that counts. International Journal of Stress Management. 16, 249-272. doi:10.1037/a0017537

Schaufeli, W.B., Bakker, A.B., van der Heijden, F.M.M.A., \& Prins, J.T. (2009b). Workaholism, burnout and well-being among junior doctors: The mediating role of role conflict. Work Eु Stress, 23, 155-172. doi:10.1080/02678370902834021

Schaufeli, W.B., Shimazu, A., \& Taris, T.W. (2009). Being driven to work excessively hard: The evaluation of a two-factor measure of workaholism in the Netherlands and Japan. Cross-Cultural Research, 43, 320 348. doi:10.1177/1069397109337239

Schaufeli, W.B., Taris, T.W., \& Bakker, A (2006). Dr. Jekyll and Mr. Hyde: On the differences between work engagement and workaholism. In R. Burke (Ed.), Research companion to working time and work addiction (pp. 193-217). Northampton, MA: Edward Elgar.

Shaffer, H.J., LaPlante, D.A., LaBrie, R.A. Kidman, K.C., Donato, A.N., \& Stanton, M.V. (2004). Toward a syndrome model of addiction: Multiple expressions, common etiology. Harvard Review of Psychiatry, 12 367-374.

Shimazu, A., Demerouti, E., Bakker, A.B., Shimada, K., \& Kawakami, N. (2011). Workaholism and well-being among Japanese dual-earner couples: A spillovercrossover perspective. Social Science $\mathbb{E}$ Medicine, 73, 399-409. doi:10.1016/j. socscimed.2011.05.049

Spence, J.T., \& Robbins, A.S. (1992). Workaholism: Definition, measurement, and preliminary results. Journal of Personality Assessment, 58, 160-178. doi:10.1207/ s15327752jpa5801_15

Stoeber, J., Davis, C.R., \& Townley, J. (2013). Perfectionism and workaholism in employees: The role of work motivation Personality and Individual Differences, 55, 733-738. doi:10.1016/j.paid.2013.06.001

Sussman, S. (2012). Workaholism: A review. Journal of Addiction Research and Theory, Suppl. 6, 4120. doi:10.4172/2155-6105. S6-001

Sussman, S., Arpawong, T.E.M., Sun, P., Tsai, J., Rohrbach, L.A., \& Sprutjt-Metz, D (2014). Prevalence and co-occurrence of addictive behaviors among former alternative high school youth. Journal of Behavioral Addictions, 3, 33-40. doi:10.1556/ JBA.3.2014.005

Sussman, S., Lisha, N., \& Griffiths, M.D. (2011). Prevalence of the addictions: A problem of the majority or the minority? Evaluation and the Health Professions, 34 3-56. doi:10.1177/0163278710380124

Taris, T.W., Schaufeli, W., \& Shimazu, A. (2010). The push and pull of work: The differences between workaholism and work engagement. In A.B. Bakker \& M.P. Leite (Eds.), Work engagement. A handbook of essential theory and research (pp. 39-53). Hove, UK: Psychological Press.

van Beek, I., Hu, Q., Schaufeli, W.B., Taris T.W., \& Schreurs, B.H.J. (2012). For fun, love, or money: What drives workaholic, engaged, and burned-out employees at work? Applied Psychology, 61, 30-55. doi:10.1111/j.1464-0597.2011.00454.x

van Beek, I., Taris, T.W., \& Schaufeli, W.B. (2011). Workaholic and work engaged employees: Dead ringers or worlds apart? Journal of Occupational Health Psychology,
16, 468-482. doi:10.1037/a0024392

Van den Broeck, A., Schreurs, B., De Witte, H., Vansteenkiste, M., Germeys, F., \& Schaufeli, W. (2011). Understanding workaholics' motivations: A self-determination perspective. Applied Psychology, 60, 600-621. doi:10.1111/j.1464-0597.2011.00449.x

Villella, C., Martinotti, G., Di Nicola, M. Cassano, M., La Torre, G., Gliubizzi, M.D.,.. Conte, G. (2011). Behavioural addictions in adolescents and young adults: Results from a prevalence study. Journal of Gambling Studies, 27, 203-214. doi:10.1007/s10899-010 9206-0

Widyanto, L., \& Griffiths, M.D. (2006) Internet addiction: A critical review. International Journal of Mental Health and Addiction, 4, 31-51.

Dr. Quinones is Lecturer in Organizationa Behavior, Open University Business School, Open University, Walton Hall, Milton Keynes, and Mr. Griffiths is Professor of Gambling Studies and Director of the International Gaming Research Unit, Nottingham Trent University, College of Business Law \& Social Sciences, School of Social Sciences, Nottingham, United Kingdom.

The authors have disclosed no potential conflicts of interest, financial or otherwise.

Address correspondence to Cristina Quinones, PhD, BSc, MSC HRM, CPsychol, Lecturer in Organizational Behavior, Open University Business School, Open University, Walton Hall, Milton Keynes, MK7 6AA, United Kingdom; e-mail: cristina.quinones@open. ac.uk.

Received: May 21, 2015

Accepted: August 3, 2015

doi:10.3928/02793695-20150923-04 